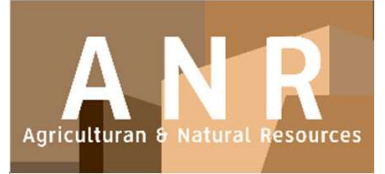

PAPER - OPEN ACCESS

\title{
Aplikasi Fungi Pada Semai Rhizophora apiculata Di Pesisir Pantai Pulau Sembilan Kecamatan Pangkalan Susu
}

\author{
Author : Y Yunasfi dkk., \\ DOI $\quad: 10.32734 /$ anr.v3i1.842 \\ Electronic ISSN : :2654-7023 \\ Print ISSN : $2654-7015$
}

Volume 3 Issue 1 - 2020 TALENTA Conference Series: Agriculturan \& Natural Resource (ANR)

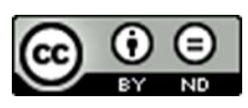

This work is licensed under a Creative Commons Attribution-NoDerivatives 4.0 International License.

Published under licence by TALENTA Publisher, Universitas Sumatera Utara

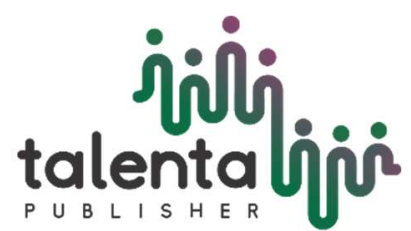




\title{
jibli

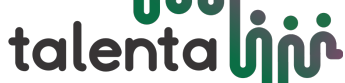 \\ ANR Conference Series 03 (2020) \\ TALENTA Conference Series
}

Available online at https://talentaconfseries.usu.ac.id/anr

\section{Aplikasi Fungi Pada Semai Rhizophora apiculata Di Pesisir Pantai Pulau Sembilan Kecamatan Pangkalan Susu}

\author{
Yunasfia, Raufan S Harahapa ${ }^{\mathrm{a}}$, Budi Utomo ${ }^{\mathrm{a}}$ \\ ${ }^{a}$ Program Studi Kehutanan, Fakultas Kehutanan, Universitas Sumatera Utara Jl. Tridarma Ujung No. 1 Kampus USU Medan 20155, Indonesia
} yunasfijamhar@yahoo.co.id

\begin{abstract}
Abstrak
Mangrove adalah salah satu sumberdaya alam pesisir yang dapat pulih dan merupakan komunitas vegetasi pesisir tropis yang didominasi oleh beberapa spesies pohon mangrove yang mampu tumbuh dan berkembang pada daerah pasang surut pantai berlumpur. Tujuan penelitian ini adalah untuk mendapatkan informasi mengenai pengaruh berbagai jenis fungi pada pertumbuhan semai R.apiculata. Penelitian ini dilaksanakan di pulau sembilan kecamatan pangkalan susu, dengan menggunakan rancangan acak lengkap (RAL) yang terdiri atas 4 perlakuan dengan 10 ulangan. Jenis fungi yang digunakan yaitu Pestalotia sp, Trichoderma harzianum, Fusarium verticilliodes serta adanya kontrol sebagai pembanding. Pemberian fungi memberikan pengaruh pada pertambahan tinggi tanaman R.apiculata dengan tinggi rata-rata $65,59 \mathrm{~cm}$ pada perlakuan fungi Trichoderma harzianum. Diameter rata-rata yang diperoleh dari perlakuan fungi Fusarium verticilliodes adalah sebesar 1,47 cm. Pertambahan lebar daun rata-rata sebesar 4,04 cm pada perlakuan Kontrol. Jumlah daun tertinggi terdapat pada perlakuan fungi Fusarium verticilliodes yaitu sebanyak 14 helai. Fungi yang paling banyak memberikan pengaruh pada pertambahan pertumbuhan bibit R.apiculata terdapat pada fungi Fusarium verticilliodes.
\end{abstract}

Kata Kunci: Fungi; Mangrove; Pertumbuhan; Rhizophora apiculata

\section{Pendahuluan}

Pada ekosistem hutan mangrove, umumnya hanya ditemukan sekitar 100 jenis tumbuhan, dibandingkan dengan ribuan jenis yang tumbuh pada ekosistem terestrial lainnya. Meskipun kekayaan jenisnya tidak setinggi ekosistem terestrial lain, hutan mangrove memiliki nilai ekologi yang sangat tinggi. Akumulasi sedimen sungai dan pasang surut air laut yang terperangkap oleh akar tumbuhan menjadikan hutan mangrove sebagai tempat tumbuh yang subur dan kaya bahan organik [1].

Menurut [1], Substrat yang terkumpul juga ditempati hewan-hewan ecosystem engineer, seperti tiram dan teritip. Vegetasi yang tumbuh menjadi habitat yang baik untuk serangga serta tempat singgah atau bersarang bagi beraneka jenis burung. Tentunya melalui fotosintesis, tumbuhan mangrove menyediakan sumber energi pada seluruh ekosistem. Dengan demikian, mangrove menjadi salah satu ekosistem yang paling produktif di dunia dan berbeda secara biologis.

Mangrove merupakan salah satu ekosistem langka, karena luasnya hanya $2 \%$ permukaan bumi. Indonesia merupakan kawasan ekosistem mangrove terluas di dunia. Ekosistem ini memiliki peranan ekologi, sosial-ekonomi, dan sosia-budaya yang sangat penting, misalnya menjaga stabilitas pantai dari abrasi, sumber ikan, udang dan keanekaragaman hayati lainnya, sumber kayu bakar dan kayu bangunan, serta memiliki fungsi konservasi, pendidikan, ekoturisme dan identitas budaya. Tingkat kerusakan ekosistem mangrove dunia, termasuk Indonesia sangat cepat akibat pembukaan tambak, penebangan hutan mangrove, pencemaran lingkungan, reklamasi dan sedimentasi, 
pertambangan, sebab-sebab alam seperti badai/tsunami, dan lain-lain. Restorasi mangrove mendapat perhatian luas mengingat tingginya nilai sosial-ekonomi dan ekologi ekosistem ini. Restorasi dapat menaikkan nilai sumber daya hayati mangrove, memberi mata pencaharian penduduk, mencegah kerusakan pantai, menjaga biodiversitas, produksi perikanan, dan lain-lain [2].

Hutan mangrove merupakan tipe hutan yang terdapat hampir di sepanjang garis pantai kepulauan di Indonesia. Sebuah kawasan hutan mangrove mengalami tekanan oleh berbagai kepentingan pembangunan. Penggunaan kawasan mangrove seringkali tidak memperhatikan kaidah-kaidah pelestarian alam sehingga menyebabkan terjadinya penurunan kualitas dan kuantitas secara drastis. Pembangunan ekonomi melalui sektor perikanan khususnya budidaya tambak, pengembangan pemukiman dan pengembangan pelabuhan merupakan kegiatan yang mempunyai andil dalam penurunan luas mangrove di Indonesia. Berbagai upaya telah dilakukan oleh Pemerintah dan masyarakat dalam rangka menjaga kelestarian hutan mangrove sebagai kawasan konservasi. Namun demikian upaya yang dilakukan melalui rehabilitasi tidak sebanding dengan kerusakan yang terjadi.

Menurut [3], deforestasi pada kawasan suaka alam dan kawasan pelestarian alam diantaranya merupakan hutan mangrove pada periode tahun 2009/2010 mencapai 25.336,20 hektar/tahun sementara upaya rehabilitasi yang dilakukan hanya mampu seluas 568 hektar pada tahun 2010 dan 10.431 hektar pada tahun 2011.

Sebagai ekosistem keberadaan hutan magrove telah memberikan manfaat bagi manusia dan lingkungan sekitarnya. Pada perkembangannya hutan mangrove hanya dipandang sebagai objek yang memberikan manfaat ekonomi. Fungsi dan manfaat ekologi mangrove kurang mendapat perhatian. Fungsi ekologis mangrove selain dapat dikembangkan sebagai kawasan konservasi juga sebagai penyimpan karbon. R.apiculata merupakan salah satu jenis tanaman penyusun vegetasi mangrove yang juga berfungsi sebagai penyimpan karbon melalui proses fotosintesis.

\subsection{Tujuan Penelitian}

Mendapatkan informasi mengenai pengaruh berbagai jenis fungi pada semai R.apiculata di pesisir pantai pulau sembilan kecamatan pangakalan susu.

\subsection{Manfaat Penelitian}

Memperoleh informasi tentang pengaruh fungi tertinggi terhadap pertumbuhan semai R.apiculata dengan perlakuan berbagai jenis fungi di pesisir pantai pulau sembilan kecamatan pangkalan susu.

\subsection{Hipotesis Penelitian}

Adanya pengaruh pemberian fungi Pestalotia sp, Trichoderma harzianum dan Fusarium verticilliodes terhadap pertumbuhan bibit $\mathrm{R}$ apiculata.

\section{Metode Penelitian}

\subsection{Lokasi Penelitian}

Penelitian pengaplikasian fungi di mulai dengan peremajaan fungi menggunakan metode PDA di Laboratorium Hama dan Penyakit Tumbuhan Fakultas Pertanian Universitas Sumatera Utara. kemudian penanaman semai Rhizophora apiculata dilakukan di pesisisr pantai Pulau Sembilan di kecamatan Pangkalan susu.

\subsection{Alat dan Bahan}

Alat yang digunakan dalam penelitian ini antara lain Cawan petri, Erlen meyer, gelas ukur, kalifer (jangka sorong), parang, gunting, termometer, penggaris/meteran, kompor, oven, mikroskop cahaya, timbangan analitik, gelas beker, jarum ose, Gelas objek, dan kamera. Bahan yang di gunakan antara lain bibit Rhizhophora apiculata berumur 3 bulan, berbagai jenis fungi (Pestalotia sp, Trichoderma harzianum, Fusarium verticilliodes), kayu pancang/ajir, alat tulis, 
tali plastik, alkohol, akuades, kertas tisu, kapas, kentang, dextrose, agar, masker, cling wrap, kertas stensil, aluminium foil, dan kertas label.

\subsection{Prosedur Kerja}

\subsubsection{Peremajaan Fungi}

Pembuatan fungi dilakukan menggunakan media buatan agar - agar kentang (PDA). Kentang dipilih karena kentang merupakan media yang mudah untuk di gunakan sebagai wadah perkembang biakan fungi, Adapun kegiatan pembuatan nya Antara lain 40 gram per liter air, diaduk hingga merata dan mendidih ( \pm 10 menit), media dituangkan ke dalam labu Erlenmeyer, ditutup kapas dan aluminium foil, media dalam labu dimasukkan ke dalam otoklaf untuk disterilisasi pada suhu $121^{\circ} \mathrm{C}$ pada tekanan 1 atm selama 15 menit. Semua pekerjaan dilakukan secara aseptik. Kemudian tuangkan sedikit cairan PDA ke cawan petri dan masukan sampel fungi yang akan dikembangkan/diperbanyak, dimasukkan kedalam autoklaf pada suhu $121{ }^{\circ} \mathrm{C}$ pada tekanan 1 atm selama 15 menit, kemudian dipanaskan kembali ke oven pada suhu $100^{\circ} \mathrm{C}$.

\subsubsection{Penanaman Bibit}

Kegiatan penanaman diawali dengan persiapan lahan. Persiapan lahan bertujuan untuk menciptakan kondisi lingkungan yang mampu meningkatkan persentase pertumbuhan propagul. Pelaksanaan penanaman bibit $R$. apiculata dilakukan dengan jarak satu meter antara bibit yang satu dengan yang lainnya. Pemasangan ajir dilakukan dengan menancapkan ajir tersebut di tempat yang sebelumnya telah diberi jarak satu meter. Pemasangan ajir ini bertujuan untuk mempermudah mengetahui tempat bibit yang ditanam, menyeragamkan jarak tanam dan sebagai tempat penegak bibit yang ditanam agar tidak roboh. Kemudian membuat lubang di tempat ajir yang telah dipasang setinggi pollybag. Membuka sebagian polibag agar akar yang telah tumbuh dapat keluar dan tumbuh dengan baik, kemudian masukkan bibit ke dalam lubang tanam yang sudah disediakan setelah itu dilanjutkan dengan penimbunan tanah agar bibit mangrove tertanam ke dalam lubang tanam, kemudian mengikat bibit pada ajir dan membuang sebagian polibag yang terbuka pada tempat sampah dan di bagi 4 plot yaitu 3 plot perlakuan fungi terhadap semai R.apiculata dan 1 plot sebagai kontrol. Jumlah bibit semai per plot adalah 40 bibit.

\subsubsection{Aplikasi Fungi Terhadap Semai}

Pengaplikasian dilakukan dengan cara mengambil sampel fungi yang telah ditentukan ke dalam gelas ukur $10 \mathrm{~mm}$ Dengan menggunakan air sebagai penyebar fungi terhadap semai agar penyebaran fungi menjadi efisien. Setiap sampel fungi yang di ambil berukuran $1 \mathrm{~cm}$ kemudian di masukkan kedalam gelas ukur yang telah berisi air sebanyak $10 \mathrm{~mm}$. Untuk perlakuan terhadap semai menggunakan cara penyiraman di area sekitar bibit semai. Setiap satu bibit semai diberikan $1 \mathrm{~cm}$ sampel fungi dengan $10 \mathrm{~mm}$ air gelas ukur. Sebelum menyiram fungi tersebut harus diaduk (shake) terlebih dahulu guna untuk mempercepat larut nya fungi. Proses pengaplikasian fungi tersaji pada Gambar 1.

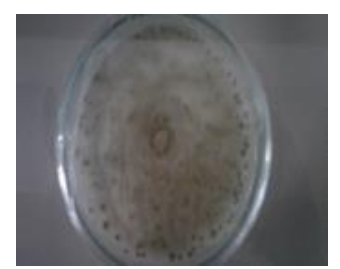

(a)

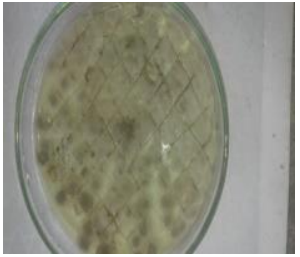

(b)

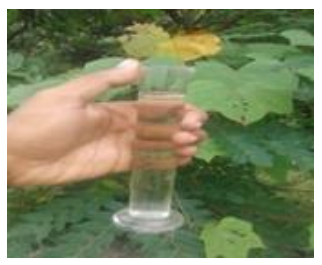

(c)

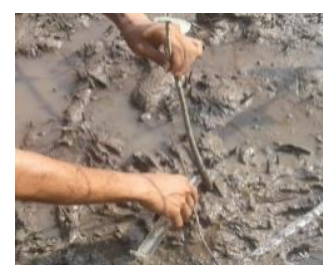

(d)

Gambar 1. Proses pengaplikasian fungi pada semai R.apiculata (a) Fungi (b) Fungi yang telah di potong per $1 \mathrm{~cm}$ (c) Fungi yang telah di masukkan kedalam gelas ukur (d) Penyebaran fungi ke area semai.

\subsubsection{Parameter yang Diamati}

Parameter yang di amati dalam penelitan ini adalah

1. Tinggi batang 
Pertumbuhan tinggi di ukur menggunakan meteran kain, atau penggaris, yang di ukur mulai dari permukaan tanah sampai titik tumbuh tanaman (pucuk).

2. Diameter batang

Pengukuran diameter batang (tunas) dilakukan dengan menggunakan jangka sorong, yang di ukur $10 \mathrm{~cm}$ dari ujung tunas propagul.

3. Lebar daun terlebar

Pengukuran daun terlebar di ukur menggunakan meteran kain, atau penggaris, yang di ukur mulai dari sisi daun hingga ke sisi daun lainnya.

4. Jumlah keseluruhan daun

Penghitungan dilakukan dengan cara menghitung jumlah keseluruhan daun yang tumbuh pada tanaman.

\subsubsection{Rancangan Percobaan}

Penanaman bibit $R$. apiculata dilakukan dipesisir pantai pulau sembilan kecamatan pangkalan susu. Penelitian ini menggunakan rancangan acak lengkap (RAL) yaitu 4 perlakuan dengan 6 ulangan. Adapun jenis fungi yang dapat digunakan untuk pertumbuhan $R$. apiculata yaitu:

a. Kontrol (R. apiculata tanpa fungi)

b. Pestalotia sp

c. Trichoderna harzianum

d. Fusarium verticilliodes

Pengumpulan data dilakukan setelah penanaman bibit dan pemberian fungi di lapangan, pada hari :

a. Hari ke-15

b. Hari ke-30

c. Hari ke-45

d. Hari ke-60

e. Hari ke-75

f. Hari ke-90

Penetapan jenis-jenis fungi ini untuk mendapatkan informasi reaksi pertumbuhan R.apiculata, untuk setiap plot terdapat 10 bibit dengan 1 perlakuan, jumlah bibit yang di teliti adalah 40 bibit. Penelitian yang dilakukan bersifat ekperimental dengan menggunakan Rancangan Acak Lengkap (RAL).

Model linier pada rancangan acak lengkap adalah seperti :

$$
Y_{i j}=\mu+\alpha_{i}+\sum_{i j}
$$

$\mathrm{Y}_{\mathrm{ij}} \quad=$ Pengamatan pada perlakuan fungi ke-i dan ulangan ke-j

$\mu \quad=$ Nilai rataan umum pengamatan

$\alpha_{\mathrm{i}} \quad=$ Faktor pemberian fungi ke-i; $\mathrm{i}=1,2, \ldots \ldots \mathrm{t}$ dan ulangan $\mathrm{ke}-\mathrm{j}=1,2, \ldots \ldots \mathrm{r}$

$\sum_{\mathrm{ij}} \quad=$ Pengaruh galat pemberian fungi ke-i dan ulangan ke-j

\section{Hasil dan Pembahasan}

Pengamatan dan pengukuran yang di laksanakan selama 12 minggu di pulau Sembilan terhadap persemaian R.apiculata menunjukkan reaksi pada pertumbuhan tinggi batang, diameter batang, lebar daun, dan jumlah daun. Data pengamatan persemaian R.apiculata menunjukkan pertumbuhan pada semai tersaji pada Tabel 1. Pengamatan dilakukan pada semai R.apiculata selama 12 minggu dengan total pengamatan sebanyak 6 kali pengamatan di pulau Sembilan. 
Tabel 1. Hasil Pengamatan persemaian R.apiculata Pulau Sembilan

\begin{tabular}{llllll}
\hline \multirow{2}{*}{ Parameter pengamatan } & \multicolumn{2}{l}{ Perlakuan } & & & \\
\cline { 2 - 5 } & Kontrol & Pestalotia sp. & T.harzianum & F.verticilliodes & Satuan \\
\hline Tinggi rata rata & 56,70 & 62,99 & 65,59 & 62,73 & $\mathrm{~cm}$ \\
Diameter rata rata & 1,44 & 1,40 & 1,43 & 1,47 & $\mathrm{~cm}$ \\
Lebar daun terlebar & 4,04 & 3,93 & 3,81 & 3,79 & $\mathrm{~cm}$ \\
Jumlah daun & 11 & 12 & 10 & 14 & Helai \\
\hline
\end{tabular}

Berdasarkan hasil pengamatan yang dilakukan terhadap $R$. apiculata dari semua variabel, menunjukkan bahwa fungi memiliki peran yang berbeda pada pertumbuhan semai R.apiculata dan memiliki pengaruh yang berbeda-beda, baik dalam pertumbuhan tinggi batang semai, diameter batang semai, lebar daun semai dan jumlah daun semai.

\subsection{Tinggi Batang}

Berdasarkan pengukuran yang di laksanakan selama 12 minggu di pulau Sembilan di kecamatan pangkalan susu, di peroleh data tinggi R.apiculata yang berbeda-beda pada setiap perlakuan. Semua semai R.apiculata yang di aplikasikan dengan berbagai jenis fungi yang berbeda menunjukan reaksi pertumbuhan yang berbeda-beda. Berdasarkan pengamatan tinggi batang semai yang di lakukan di pulau sembilan, Aplikasi pemberian fungi terhadap semai R.apiculata berpengaruh nyata terhadap tinggi tanaman. Laju pertumbuhan tinggi rata rata yang lebih besar terdapat pada semai R.apiculata dengan perlakuan T.harzianum dengan rata rata tinggi adalah sebesar $65,59 \mathrm{~cm}$ dan yang terendah terdapat pada semai tanpa perlakuan (kontrol) dengan nilai rata rata 56,69 cm. Setiap $2 \mathrm{minggu}$ semai R.apiculata mengalami peningkatan pertumbuhan tinggi. Akan tetapi pada hasil uji lanjutan Duncans Multiple Range Test (DMRT) pada pertumbuhan tinggi batang semai R.apiculata tidak menunjuk kan pengaruh nyata karena pada perlakuan T.harzianum, Pestalotia sp dan F.verticilliodes memiliki data nilai rata-rata perlakuan yang di ikuti huruf yang sama yaitu, (a) dan hanya pada perlakuan kontrol dengan nilai rata rata berlabel huruf (b) yang berbeda pengaruh nya diantara perlakuan lainnya. Hasil uji lanjutan tersaji pada Tabel 2.

Tabel 2. Hasil uji lanjutan DMRT pada pertumbuhan tinggi tanaman R.apiculata

\begin{tabular}{ll}
\hline Perlakuan & Pertambahan tinggi tanaman $(\mathrm{cm})$ \\
\hline Trichoderma harzianum & $65,59 \mathrm{a}$ \\
Pestalotiasp & $62,98 \mathrm{a}$ \\
Fusarium verticilliodes & $62,73 \mathrm{a}$ \\
Kontrol & $56,70 \mathrm{~b}$ \\
\hline
\end{tabular}

Keterangan: Angka yang diikuti huruf yang sama memiliki nilai yang tidak berpengaruh nyata dengan nilai uji lain pada uji Duncan 5\%.

Laju pertumbuhan tinggi semai R.apiculata dapat dilihat pada Tabel 3.

Tabel 3. Hasil laju pertumbuhan tinggi Rhizhopora apiculata selama 12 minggu

\begin{tabular}{lllll}
\hline Pengamatan ke- & Kontrol & Pestalotia sp & Trichoderma harziamun & $\begin{array}{l}\text { Fusarium } \\
\text { verticilliodes }\end{array}$ \\
\hline 1 & 50,88 & 55,06 & 55,15 & 54,62 \\
2 & 52,96 & 58,72 & 58,97 & 57,38 \\
3 & 55,61 & 62,07 & 63,38 & 61,43 \\
4 & 57,81 & 64,74 & 67,63 & 64,56 \\
5 & 60,38 & 67,39 & 71,98 & 67,82 \\
6 & 62,53 & 69,96 & 76,44 & 70,56 \\
\hline
\end{tabular}


Berdasarkan hasil pengamatan, laju pertumbuhan tinggi batang semai menunjukkan bahwa setiap pengamatan mengalami pertambahan tumbuh tinggi pada setiap perlakuan. Laju pertumbuhan tinggi paling besar terdapat pada perlakuan T.harzianum dengan hasil pengamatan akhir yaitu, $76,44 \mathrm{~cm}$ dan untuk laju pertumbuhan terkecil terdapat pada perlakuan tanpa perlakuan (Kontrol) dengan hasil akhir pengamatan yaitu, $62,53 \mathrm{~cm}$. Grafik laju pertumbuhan tinggi selama 12 minggu tersaji pada Gambar 2.

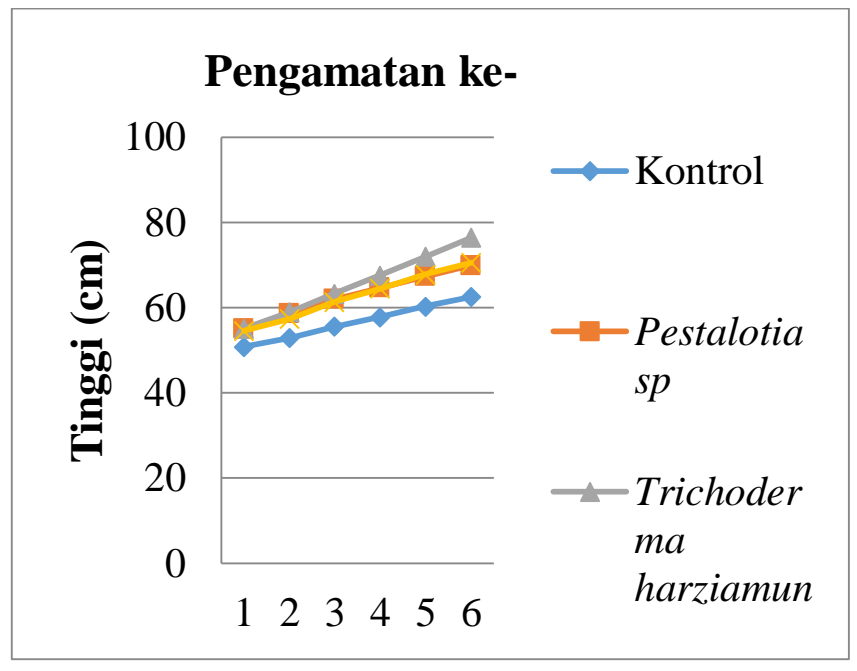

Gambar 2. Pengukuran Tinggi semai R.apiculata Pulau Sembilan

Pertambahan tinggi dapat di pengaruhi oleh salinitas, umur tanaman dan faktor lingkungan lainnya. Hal ini didukung oleh [4] yang menyatakan bahwa Salinitas air dan salinitas tanah rembesan merupakan faktor penting dalam pertumbuhan, daya tahan, dan zonasi spesies mangrove. Tumbuhan mangrove tumbuh subur di daerah estuaria dengan salinitas 10-30 ppt. Salinitas yang sangat tinggi (hypersalinity) misalnya ketika salinitas air permukaan melebihi salinitas yang umum di laut ( $\pm 35 \mathrm{ppt})$ dapat berpengaruh buruk pada vegetasi mangrove, karena dampak dari tekanan osmotik yang negatif. Keberhasilan pertumbuhan semai tergantung pada tiga faktor yaitu suhu, ketersediaan air dan kemampuan semai dalam memproduksi akar [5].

Pada hutan mangrove pertumbuhan tinggi dan diameter batang R.apiculata akan bertambah dengan bertambahnya umur, namun terjadi perbedaan dengan perbedaan lokasi dan kondisi lingkungan [6].

\subsection{Diameter Batang}

Berdasarkan pengamatan yang telah dilaksanakan di lapangan menunjukkan bahwa pengaplikasian fungi terhadap R.apiculata tidak berpengaruh nyata terhadap pertumbuhan diameter batang R.apiculata karena F. Hitung lebih rendah dari nilai F. Tabel. Data diameter batang dan analisis sidik ragam terlampir pada (Lampiran 3 dan Lampiran 4). Aplikasi fungi pada pertumbuhan diameter batang semai R.apiculata menunjukkan perkembangan tumbuh diameter. Hasil rata- rata pengukuran diameter tersaji pada tabel 1. Dari hasil pengukuran diameter dapat di simpulkan bahwa perlakuan F.verticilliodes memiliki pengaruh pertumbuhan diameter lebih besar dari pada perlakuan lainnya dengan nilai rata-rata 1,47 cm sementara yang terendah terdapat pada perlakuan Pestalotia sp dengan nilai rata-rata 1,40 cm. Laju pertumbuhan diameter batang R.apiculata tersaji pada Tabel 4.

Tabel 4. Hasil laju pertumbuhan diameter R.apiculata selama 12 minggu

\begin{tabular}{lllll}
\hline Pengamatan ke- & Kontrol & Pestalotia sp & $\begin{array}{l}\text { Trichoderma } \\
\text { harzianum }\end{array}$ & $\begin{array}{l}\text { Fusarium } \\
\text { verticilliodes }\end{array}$ \\
\hline 1 & 1,246 & 1,237 & 1,224 & 1,271 \\
2 & 1,352 & 1,305 & 1,307 & 1,358 \\
3 & 1,409 & 1,375 & 1,39 & 1,438 \\
\hline
\end{tabular}




\begin{tabular}{lllll}
\hline 4 & 1,485 & 1,437 & 1,475 & 1,515 \\
5 & 1,55 & 1,494 & 1,552 & 1,587 \\
6 & 1,612 & 1,552 & 1,617 & 1,662 \\
\hline
\end{tabular}

Hasil pengamatan laju pertumbuahan diameter batang semai R.apiculata menunjukkan bahwa setiap pengamatan mengalami pertambahan diameter 2 setiap minggu sekali, hasil pengamatan akhir tertinggi terdapat pada perlakuan penambahan fungi F.verticilliodes dengan nilai $1,662 \mathrm{~cm}$ kemudian hasil pengamatan akhir dengan nilai terendah terdapat pada perlakuan Pestalotia $s p$ dengan nilai $1,552 \mathrm{~cm}$. Grafik laju pertumbuhan diameter batang semai R.apiculata tersaji pada Gambar 3.

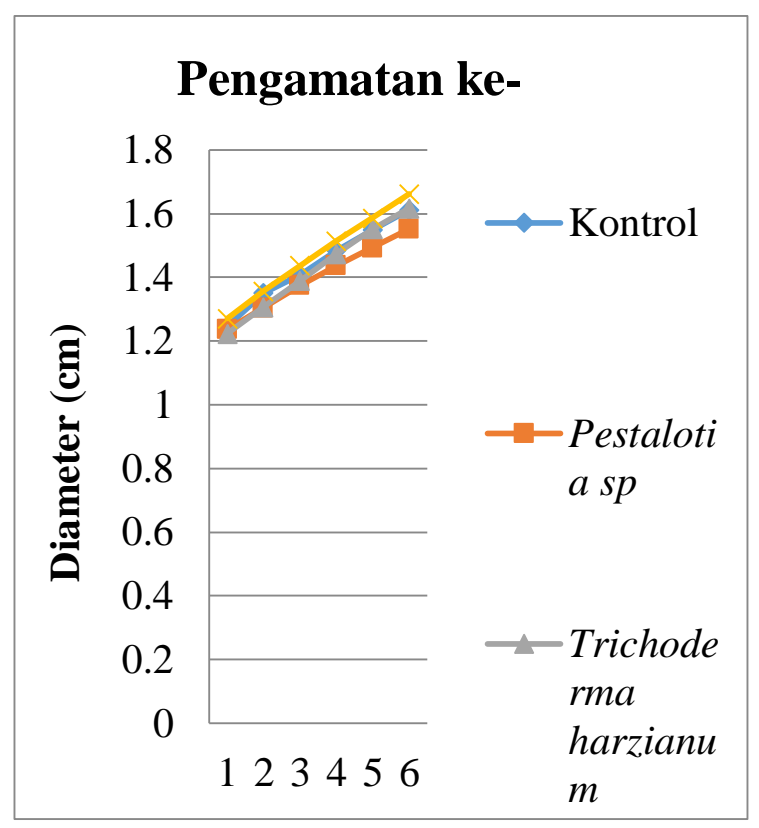

Gambar 3. Pengukuran diameter semai R.apiculata pulau Sembilan

Menurut [7], pertumbuhan diameter batang di pengaruhi oleh kandungan unsur K yang berperan penting dalam aktivitas pembelahan sel dan perkembangan jaringan meristematik tanaman yang berakibat dalam pembesaran batang. Salah satu bentuk interaksi antara satu populasi dengan populasi yang lain atau antara individu dengan individu yang lain adalah bersifat persaingan. Persaingan dapat terjadi apa bila sarana pertumbuahan atau bahan makanan unsur hara di lingkungan tidak tersedia dalam jumlah yang cukup [8].

\subsection{Lebar Daun Terlebar}

Berdasarkan hasil pengamatan yang telah di lakukan di pulau sembilan, diketahui bahwa pengaplikasian fungi terhadap semai R.apiculata menunjukkan pengaruh nyata pada pertumbuhan lebar daun. Untuk lebar daun terlebar nilai tertinggi terdapat pada semai R.apiculata pada perlakuan tanpa perlakuan (kontrol) dengan nilai rata-rata sebesar $4,04 \mathrm{~cm}$, dan untuk nilai terendah terdapat pada perlakuan F.verticilliodes dengan nilai rata rata sebesar $3,79 \mathrm{~cm}$. Perbedaan lebar daun terlebar tersaji pada gambar 4. 


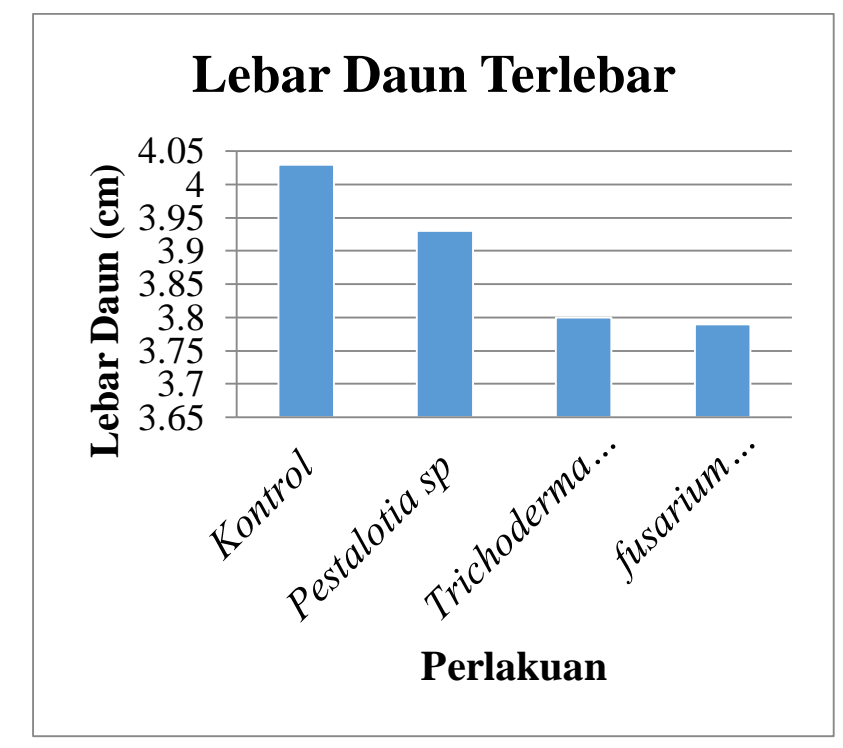

Gambar 4. Grafik lebar daun terlebar R.apiculata pulau Sembilan

Pada hasil uji lanjutan DMRT pada pertumbuhan lebar daun terlebar R.apiculata menunjukkan perlakuan kontrol (a) dan pestalotia sp (ab) tidak berbeda nyata pengaruhnya sama seperti perlakuan T.harzianum (bc) dengan F.verticilliodes (c) tidak berbeda nyata pengaruh nya pada pertumbuhan lebar daun terlebar akan tetapi perlakuan Kontrol dan Pestalotia sp dengan perlakuan T.harzianum dan F.verticilliodes akan berpengaruh nyata pada pertumbuhan lebar daun semai R.apiculata dapat dilihat pada Tabel 5.

Tabel 5. Hasil uji lanjutan DMRT pada pertumbuhan lebar daun terlebar tanaman R.apiculata

\begin{tabular}{ll}
\hline Perlakuan & Pertambahan lebar daun terlebar $(\mathrm{cm})$ \\
\hline Kontrol & $4,04 \mathrm{a}$ \\
Pestalotia sp & $3,93 \mathrm{ab}$ \\
Trichooderma harzianum & $3,81 \mathrm{bc}$ \\
Fusarium verticilliodes & $3,76 \mathrm{c}$ \\
\hline
\end{tabular}

Keterangan: Angka yang di ikuti huruf yang sama memiliki nilai yang tidak berpengaruh nyata dengan nilai uji lain pada uji Duncan $5 \%$.

Pertumbuhan lebar daun dapat di pengaruhi oleh intensitas cahaya dan suhu lingkungan. Apabila jumlah intensitas cahaya yang di butuhkan cukup maka pertumbuhan daun akan semakin baik dan apa bila jumlah intensitas cahaya yang rendah maka pertumbuhan daun akan buruk. Menurut [9], salah satu faktor dari fotosintesis adalah cahaya dan fotosintesis merupakan proses yang sangat di butuhkan oleh tanaman hijau untuk pertumbuhan. Proses respirasi, transpirasi dan struktur fisik tanaman di pengaruhi oleh cahaya, lamanya penyinaran serta intensitas cahaya juga merupakan faktor penting bagi tanaman. Tanaman mangrove umumnya membutuhkan intensitas cahaya yang tinggi.

\subsection{Jumlah Daun}

Berdasarkan hasil pengamatan yang dilakukan di pulau Sembilan, pengaplikasian fungi terhadap semai R.apiculata tidak berpengaruh nyata terhadap pertumbuhan jumlah daun. Jumlah daun pada semai R.apiculata merupakan faktor penting dalam pertumbuhan semai. Semai R.apiculata dapat berfotosintesis dengan baik. Adapun nilai tertinggi pada pertumbuhan jumlah daun semai R.apiculata terdapat pada perlakuan F.verticilliodes dengan nilai rata rata 14 helai daun, dan nilai terendah terdapat pada perlakuan T.harzianum dengan nilai rata rata 10 helai daun. Perbedaan pertumbuhan jumlah daun tersaji pada Gambar 5. 


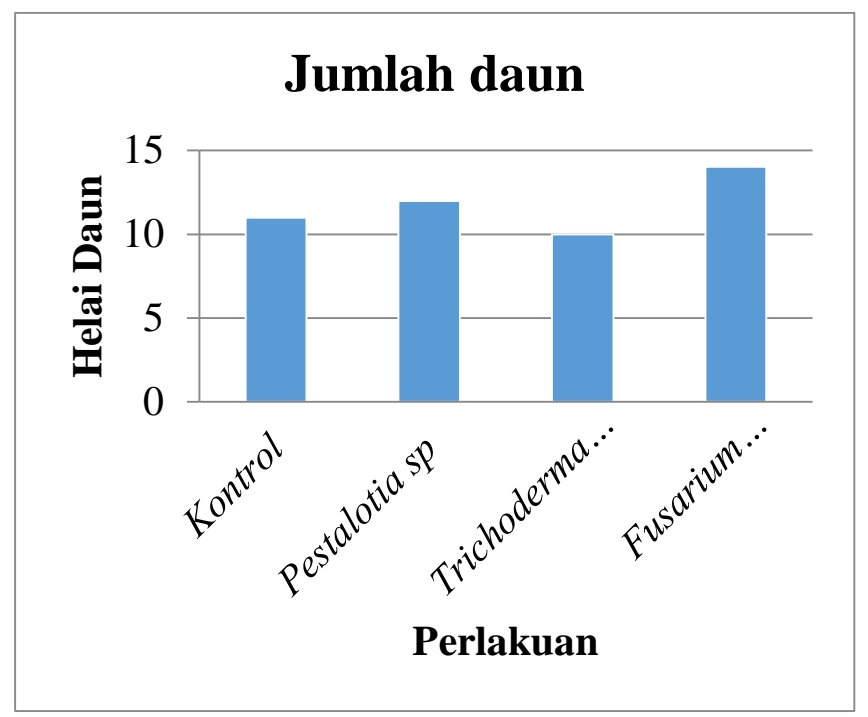

Gambar 5. Grafik jumlah daun R.apiculata pulau Sembilan

Hal ini disebabkan oleh pengaruh lingkungan seperti intensitas cahaya dan unsur hara. Menurut [10], intensitas cahaya yang terlalu tinggi dapat menyebabkan transpirasi yang terlalu besar sedangkan intensitas cahaya yang terlalu rendah akan menghambat fotosintesa sehingga menghambat pertumbuhan tanaman.

Kemudian [11], menyatakan bahwa rendah nya unsur hara $\mathrm{N}$ pada media tanam dapat menyebabkan terhambat nya pertumbuhan organ vegetatif seperti daun dan cabang baru. Jumlah keseluruhan pertambahan pertumbuhan semai R.apiculata selama 12 minggu tersaji pada Tabel 6.

Tabel 6. Jumlah seluruh pertambahan pertumbuhan semai R.apiculata selama 12 minggu

\begin{tabular}{llllll}
\hline \multirow{2}{*}{ Parameter pengamatan } & \multicolumn{2}{c}{ Perlakuan } & & & \\
\cline { 2 - 5 } & Kontrol & Pestalotiasp & T.harzianum & F.verticilliodes & Satuan \\
\hline Tinggi Batang & 11,65 & 14,9 & 21,29 & 15,94 & $\mathrm{Cm}$ \\
Diameter Batang & 0,366 & 0,315 & 0,393 & 0,391 & $\mathrm{Cm}$ \\
Lebar Daun Terlebar & 1,366 & 1,235 & 1,044 & 1,01 & $\mathrm{Cm}$ \\
Jumlah Daun & 14 & 19 & 14 & 20 & Helai \\
\hline
\end{tabular}

Berdasarkan hasil pengamatan pertambahan tumbuh tanaman R.apiculata selama 12 minggu, pertambahan tetinggi pada variabel tinggi terdapat pada perlakuan penambahan T.harzianum dengan nilai jumlah pertumbuhan $21,29 \mathrm{~cm}$ sedangkan pertumbuhan terendah terdapat pada perlakuan kontrol dengan nilai jumlah pertumbuhan $11,65 \mathrm{~cm}$ selama 12 minggu pengamatan, pada veriabel diameter batang pertambahan diameter tertinggi terdapat pada perlakuan F.verticilliodes yaitu, $0,391 \mathrm{~cm}$ dan untuk pertambahan diameter terendah terdapat pada perlakuan Pestalotiasp dengan nilai $0,315 \mathrm{~cm}$ selama 12 minggu, sedangkan pada variabel lebar daun terlebar perlakuan kontrol merupakan pertambahan lebar daun terbaik dengan nilai $1,366 \mathrm{~cm}$ selama 12 minggu dan nilai $1,01 \mathrm{~cm}$ merupakan nilai terendah pertambahan lebar daun selama 12 minggu yang tedapat pada perlakuan F.verticilliodes kemudian variabel terakhir adalah jumlah daun, pertambahan pertumbuhan jumlah daun terbaik terdapat pada perlakuan F.verticilliodes yaitu, 20 cm selama 12 minggu dan pertambahan terendah terdapat pada perlakuan T.harzianum yaitu, $14 \mathrm{~cm}$ selama 12 minggu.

Rata-rata pertambahan pertumbuhan semai R.apiculatasetiap kali pengamatan (2 minggu sekali) dapat dilihat Pada Tabel 7. 
Tabel 7. Rata-rata pertambahan pertumbuhan semai R.apiculatasetiap kali pengamatan (2 minggu sekali).

\begin{tabular}{llllll}
\hline & \multicolumn{2}{l}{ Perlakuan } & & & \\
\cline { 2 - 5 } Parameter pengamatan & Kontrol & Pestalotia sp & $\begin{array}{l}\text { T. } \\
\text { harzianum }\end{array}$ & $\begin{array}{l}\text { S. } \\
\text { verticilliodes }\end{array}$ & Satuan \\
\hline Tinggi Batang & 1,942 & 2,483 & 3,548 & 2,657 & $\mathrm{Cm}$ \\
Diameter Batang & 0,061 & 0,053 & 0,066 & 0,065 & $\mathrm{Cm}$ \\
Lebar Daun Terlebar & 0,228 & 0,206 & 0,174 & 0,168 & $\mathrm{Cm}$ \\
Jumlah Daun & 2,33 & 3,1 & 2,28 & 3,25 & Helai \\
\hline
\end{tabular}

Berdasar kan pada Tabel 7, Rata-rata pertambahan pertumbuhan semai R.apiculata setiap kali pengamatan (2 kali seminggu) menunjukkan bahwa pertambahan pertumbuhan tertinggi pada tinggi batang semai terdapat pada perlakuan T.harzianum dengan nilai rata rata $3,548 \mathrm{~cm}$ dan terendah terdapat pada perlakuan kontrol dengan nilai $1,942 \mathrm{~cm}$, untuk pertambahan tumbuh diameter terbaik terdapat pada perlakuan T.harzianum dengan nilai rata-rata $0,066 \mathrm{~cm}$ dan pertambahan tumbuh terendah terdapat pada perlakuan Pestalotia sp dengan nilai rata rata $0,053 \mathrm{~cm}$. Sedangkan pada variabel lebar daun pertambahan tumbuh tertinggi dengan rata rata $0,228 \mathrm{~cm}$ pada perlakuan kontrol dan terendah dengan rata rata $0,168 \mathrm{~cm}$ pada perlakuan F.vertilliodes kemudian pada variabel jumlah daun rata rata terbaik 3,25 helai terdapat pada perlakuan F.verticilliodes sedangkan rata-rata terendah terdapat pada perlakuan $T$. harzianum yaitu, 2,28 helai.

\section{Kesimpulan dan Saran}

\subsection{Kesimpulan}

Fungi mempunyai peran yang berbeda beda dalam pertumbuhan semai Rhizophora apiculata pada variabel tinggi batang, diameter batang, lebar daun terlebar dan jumlah daun. Pengaplikasian fungi yang berpengaruh nyata hanya tedapat pada tinggi batang dan lebar daun terlebar dan yang tidak berpengaruh nyata terdapat pada diameter batang dan jumlah daun. Fungi yang paling mempengaruhi pertumbuhan Rhizophora apiculata terdapat pada perlakuan Fusarium verticilliodes dengan nilai data tertinggi di dua variable dari empat variable yaitu variabel diameter batang dengan nilai $1,47 \mathrm{~cm}$ dan variabel jumlah daun dengan nilai 14 helai daun.

\subsection{Saran}

Sebaiknya dilakukan uji lanjutan mengenai fungsi fungi pada pertumbuhan, agar dapat mendalami lebih spesifik mengenai pengaruh fungi terhadap pertumbuhan tanaman bakau dan mengetahui bagaimana reaksi perkembangan tumbuh tanaman.

\section{Referensi}

[1] Hogart, P. (2007) “The Biology of Mangroves and Seagrasses", New York, Oxford University Press

[2] Setyawan, A.D. (2002) “Ekosistem Mangrove Sebagai Kawasan PeralihanEkosistem Perairan Tawar dan Perairan Laut.” Enviro 2 (1): $25-40$.

[3] Kementerian Kehutanan (2012) "Deforestasi pada Kawasan Suaka Alam dan Kawasan Pelestarian Alam"

[4] Syah C. (2011) "Pertumbuhan tanaman bakau (Rhizophora mucronata) pada lahan restorasi mangrove di hutan lindung Angke Kapuk provinsi DKI Jakarta", dalam Tesis, Bogor, Program Pascasarjana Institut Pertanian Bogor

[5] Daniel, T.W., J.A. Helm, dan F.S. Baker (1987) “Prinsip-Prinsip Silvikultur”, Yogyakarta, Gajah Mada University Press

[6] Aksornkoae, S. (1993) "Ecology and Management of Mangrove”, in The IUCN Wetlannds Programme, Bangkok, Thailand

[7] Herdiana N., Lukman A.H., Mulyadi K. (2008) "Pengaruh Dosis dam Frekuensi Aplikasi Pemupukan NPK terhadap Pertumbuhan Bibit Shorea ovalis Korth.” Jurnal Penelitan Hutan dan Konservasi Alam 5: 289-296. 
[8] Husnaeni, A. (2013) "Pertumbuahan Anakan Avicennia marina Dan Rhizophora mucronata Pada Jarak Tanam Yang Berbeda Dengan Menggunakan Teknik Penanaman Guludan", Sekolah Pascasarjana Institut Pertanian Bogor, Bogor

[9] Mac Nae W. (1986) “A General Account of Fauna and Flora of MagroveSwamps and Forest in The Indowest Pasific Region”, in Adv. Mar. Biol.

[10] Sudomo A. (2009) "Pengaruh Naungan Terhadap Pertumbuhan dan Mutu Bibit Manglid (Manglieta glauca BI)." Tekno Hutan Tanaman 2 (2): 59-66.

[11] Fitrianah L., Fatimah S., Hidayati Y. (2012) "Pengaruh Komposisi Media Tanam Terhadap Pertumbuhan dan Kandungan Saponin pada Dua Variates Tanaman Gendola Basella sp." Agrovigor. 5 (1): 34-46. 